\title{
Türk Ortopedi ve Travmatoloji Birliği Derneği Asistan ve Genç Uzman Hekimler (TOTBID-AGUH)
}

\author{
Turkish Society of Orthopaedics and Traumatology \\ Residents and Young Orthopaedics Surgeons (TOTBID-AGUH)
}

\author{
Gazi Huri
}

Hacettepe Üniversitesi Tıp Fakültesi, Ortopedi ve Travmatoloji Anabilim Dalı, Ankara

\begin{abstract}
Hızlı değişimlerin yaşandığı çağımızda, ortopedi biliminin geliş̧mesinde eğitim, uygulama ve güçlü işbirlikleri oldukça önem kazamıştır. TOTBiD - Asistan ve Genç Uzman Hekim Konseyi (TOTBID-AGUH) de bu noktada önemli bir rol üstlenmiştir. TOTBID-AGUH, Türk Ortopedi ve Travmatoloji Birliği Derneği (TOTBiD) bünyesinde kurulmuş, iki yılı aşkın süredir çalışmalarına devam eden ve ülkemizde genç ortopedistleri temsil eden resmi topluluktur. TOTBID-AGUH, ülkemizde Ortopedi ve Travmatoloji eğitim ve uygulamalarının geliştirilmesinde ve belirli seviyelere taşınmasında nesiller arası iletişimi sağlayacak önemli bir topluluktur.
\end{abstract}

Anahtar sözcükler: TOTBID-AGUH; genç; ortopedi; cerrah

\begin{abstract}
In this era of continuous change and evolution, orthopaedic training and education as well as strong collaborations gain even more significance. This is where the Turkish Young Orthopaedics Surgeons Council (TOTBID-AGUH) plays a major role in the field. TOTBID-AGUH is the official representative of the young orhopaedics surgeons in Turkey which was recognized by TOTBID and has been in the field for the past two years. In terms of improving the standards of orthopaedic training and standardization of the education in Turkey, TOTBID-AGUH would present a good opportunity to achieve the communication among generations.
\end{abstract}

Key words: TOTBID-AGUH; young; orthopaedics; surgeon

\section{GiRiş}

Ortopedi ve travmatoloji eğitimi tüm Dünyada benzerlikler gösterse de, eğitimin standardizasyonu ile ilgili ciddi sorunlar ve eşitsizlikler yaşanmaktadır. ${ }^{[1]}$ Özellikle Amerika ve Avrupa ile Asya ve Ortadoğu ülkeleri arasında belirgin farklılıklar bulunmaktadır. Bunun nedenleri arasında güncel tıp eğitimindeki öncelikler, ülkelerin izledikleri sağlık politikaları ve hekim motivasyonlarındaki farklar göze çarpmaktadır. Tıpta uzmanlık alanlarının birçoğunda olduğu gibi, son on yılda ortopedi eğitiminin geliştirilmesi ve kaliteli hizmet verilmesi için kurulan akreditasyon konseylerinin etkinliğinin gelişmiş ülkelerde artması, bu farkın hızla açılmasının en önemli nedenlerinden biridir. 1996 yilında Royal College of Physicians and Surgeons of Canada tarafından yayımlanan, uzmanlık eğitiminin geliştirilmesini amaçlayan genelge, ${ }^{[2]}$ Amerika Birleşik Devletleri'nde Accreditation Council for Graduate Medical Education (ACGME)'nin 1999 yilında yeniden düzenlenmesi ${ }^{[3,4]}$ bu konuda atılmış önemli adımlardandır. Yine 2006 yılında Avusturya'da ortopedi ve travmatoloji eğitiminin yeni nesillere daha iyi aktarılması için Australian Postgraduate Medical Councils, "The Australian Curriculum Framework for Junior Doctors" başlıklı bir eğitim hareketi başlatmıştır. ${ }^{[5,6]}$ Avrupa'da ise bu konuda European Union of Medical Specialists (UEMS) Specialist Section of Orthopaedics and Traumatology ile birlikte European Board of Orthopaedics and Traumatology (EBOT) tüm Avrupa ülkelerinde uygulanması amaçlanan standart bir eğitim programı geliştirmiştir. Bununla eşzamanlı olarak, EBOT ile genç ortopedistlerin eğitimi konusunda son yıllarda Federation of Orthopaedics Trainees in Europe (FORTE) de aktif bir rol almaktadır. Gerek eğitim veren kurumların gerekse uzmanlık öğrencilerin en üst seviyede eğitim almasını amaçlayan bu çalışmaları, ülkemizde Türkiye Ortopedi ve Travmataloji Eğitim Konseyi (TOTEK) yürütmektedir. Bu amaçla, 2012 yılında, Türk Ortopedi ve Travmatoloji Birliği Derneği (TOTBID) bünyesindeki asistan (tıpta uzmanlık

- İletişim adresi: Yrd. Doç. Dr. Gazi Huri, Hacettepe Üniversitesi Tıp Fakültesi, Ortopedi ve Travmatoloji Anabilim Dalı, Ankara Tel: 0312 - 3051207 e-posta: gazihuri@hacettepe.edu.tr

- Geliş tarihi: 24 Ekim $2014 \quad$ Kabul tarihi: 24 Ekim 2014 
öğrencileri) ve genç ortopedi uzmanlarının akademik, eğitsel, kişisel ve sosyal gelişimine yönelik çalışmalar planlamayı, projeler üretmeyi ve genç hekimlerin istekleri doğrultusunda onların çalışmalarına yön vermeyi amaçlayan bir yürütme kurulu olarak, TOTBiD/ AGUH (Türk Ortopedi ve Travmatoloji Birliği Derneği Asistan ve Genç Uzman Hekimler) Konseyi kurulmuştur. Bu yazıda TOTBID-AGUH Konseyi'nin kuruluşu, amaçları ve gelecek amaçlarının paylaşımı hedeflenmiştir.

\section{TARIH}

Ülkemizde ilk olarak UDEK (Uzmanlık Dernekleri Eşgüdüm Kurulu) ve Uzmanlık Derneklerinin, uzmanlık eğitiminin niteliğini arttırmak adına 1-3 Aralık 2006 tarihlerinde düzenledikleri XII. Tıpta Uzmanlık Eğitimi Kurultayı (TUEK) sonuç bildirgesinde, Asistan Hekim Kurultayı ile ilgili kararlar alınmıştır. Ankara'da 9 Haziran 2008 tarihinde, Ankara, İstanbul, İzmir, Bolu, Erzurum ve Elazığ illerinden 55 asistan hekimin katılımı ile 1. Asistan Hekim Kurultayı gerçekleştirilmiş ve uzmanlık eğitimi ile diğer ihtiyaçlara değinilmiştir. Ankara'da 28-30 Kasım 2008 tarihlerinde düzenlenen XIV. TUEK'te, ilk defa uzmanlık derneklerinden Asistan Hekim Temsilcisi istenmiş ve bu temsilcilerin TUEK'lere katılımları teşvik edilmiştir. İzmir'de 4-6 Aralık 2009 tarihlerinde düzenlenen XV. TUEK'te gerçekleştirilen “Çalışma Grupları Raporlarının Sunulması" toplantısında, asistan hekimlerin karşılaştıkları sorunların somut bir şekilde ortaya konulmasını ve çözüme giden yolu hızlandırmayı amaç edinen bir "Asistan Hekim Çalışma Grubu" kurulması önerilmiş ve bu konu, başta UDEK Başkanı Prof. Dr. İskender Sayek olmak üzere, tüm yürütme kurulu üyeleri tarafindan desteklenmiştir. Mayıs 2010 tarihinde UDEK'in katılımıyla gerçekleşen toplantıda, bu grubun asistan hekimlerin yanı sıra yeni uzmanları da kapsayacak şekilde genişletilmesine karar verilmiş ve AGUH (Asistan ve Genç Uzman Hekimler) çalışma grubu olarak faaliyetlerine başlamıştır. TOTBID 2011 yılından itibaren, UDEK bünyesinde gerçekleştirilen AGUH toplantılarına bir uzman ve bir asistan temsilcisi ile katılmakta ve geri bildirimleri değerlendirmektedir.

$\mathrm{Bu}$ gelişmeler ışığında TOTBiD Yönetim Kurulu, 2012 yılında almış olduğu kararda aynı yıl Ortopedi Buluşması'nda yapılacak seçim ile TOTBID/AGUH Konseyi kurulmasına karar vermiştir (Şekil 1). Çalışma ilkesi, ülkemizde ortopedi ve travmatoloji biliminin duayenlerinin büyük emekleri ile kurdukları "Türk Ortopedisi"nin dünyadaki saygın yerini korumak ve ilerletmek olan bu konsey, tamamen gönüllülük esasına dayanan ilkeler üzerine kurulmuştur. Beş asil ve beş yedek üyeden oluşan TOTBID/AGUH Konseyi Yürütme Kurulu, kurucu üyeler Yrd. Doç. Dr. Gazi Huri'nin başkanlığında, Dr. Sertan Çabuk, Dr. Güray Batmaz, Yrd. Doç. Dr. M. Ali Deveci ve Dr. Volkan Doğan'dan oluşmuş ve faaliyetlerine başlamıştır.

\section{AMAÇLAR VE AKTIVITELER}

Geleceğin güvencesi ve uzmanlık eğitiminin de öznesi olarak tanımlanan asistan ve genç uzman hekimlerin gelişimi ve eğitimi konuları, Dünyada hızla artan bir ivme ile önem kazanmaktadır. Bu konuda, son yıllarda asistan eğitimi sırasında karşılaşılan sorunlardan, standardizasyon ve fırsat eşitsizlikleri ön plana çıkmıştır. ${ }^{[7,8]}$ Ülkemizde de mevcut sorunları merkez alarak çizilen yol haritasında TOTBID/AGUH'nin kısa ve uzun dönem çalışma planları belirlenmiştir.

\section{Kısa dönem planları}

Kısa dönem planları arasında aşağıdaki başıklar dikkat çekmektedir:

- Ulusal ve uluslararası kursların ve toplantıların duyurularının yapılabileceği sosyal paylaşım ağlarının oluşturulması.

- Tüm asistan ve genç uzman hekimlerin iletişim adreslerini içeren veri tabanının oluşturulması.

- Avrupa genelinde uzmanlık eğitiminde ortak payda oluşturulması.

- "Federation of Orthopaedics Trainees in Europe (FORTE)" ile olan ilişkilerin güçlendirilmesi.

- Ulusal ve uluslararası toplantılarda oturumlar düzenlenmesi.

- TOTEK (Türk Ortopedi ve Travmatoloji Eğitim Kurultayı) ile çalışmalar yapıp bilimsel, eğitim ve mesleki konularda yeni anketler hazırlanması; daha önceki dönemlerde yapılmış anketlerin derlenmesi ve saygın ortopedi dergilerinde yayımlanması.

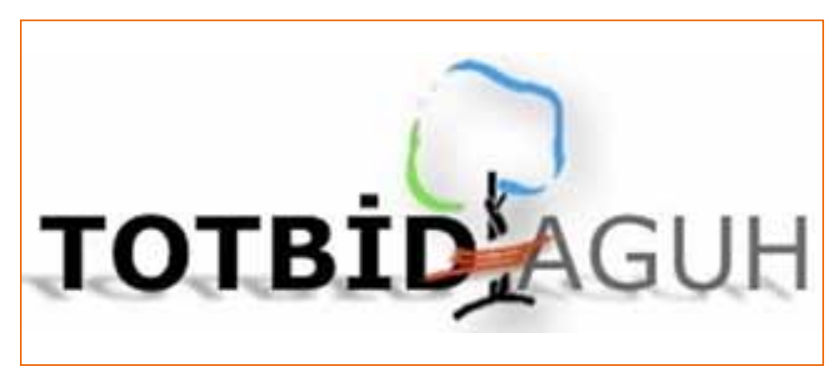

Şekil 1. TOTBID/AGUH resmi logosu. 


\section{Uzun dönem planları}

Uzun dönem planları ise aşağıdaki gibidir:

- Asistan eğitiminde geri bildirimler neticesinde tespit edilen bireysel veya yan dala özgü eksikliklerin tespit edilmesi; TOTBiD ile paylaşılıp çözüm üretilmesi.

- Genç uzman hekimlerin mesleki gelecekleri açısından kararlarını doğru yönlenmesini sağlamak adına çalışmaların yapılması.

- Mecburi hizmet yapan uzman hekimlerin eksikliklerinin, özlük haklarının korunması ve sorunlarının (bilimsel, mesleki, eğitsel ve sosyal) tespit edilip bu konuda çalışmalar yapılması.

- Genç uzmanlık sürecinde doktora eğitimi veya branşlara özgü konularda çalışmalar (fellowship) yapmak için program kriterlerinin belirlenmesi.

Yukarıda sayılan hedefler içerisinde ulusal ve uluslararası kursların ve toplantıların duyurularının yapılabileceği sosyal paylaşım ağı adresleri şunlardır;

aguh_totbid@googlegroups.com

www.facebook.com/aguhtotbid

https://twitter.com/aguhtotbid

Bunun yanı sıra, Avrupa genelinde uzmanlık eğitiminde ortak paydanın oluşturulması, eğitimin optimizasyonu ve standardizasyonu için, söylemlerimizi ve fikirlerimizi uluslararası da paylaşabileceğimiz, 2005 yılından bu yana faaliyet gösteren FORTE'ye 2012 ilk yarısında TOTBID-AGUH olarak ülke üyeliği kabul edilmiştir. Bu üyelik sürecinde, 2011 yılında düzenlenen 22. Ulusal Ortopedi ve Travmatoloji Kongresi'nde, dönemin TOTBiD başkanı Sayın Prof. Dr. Mahmut
Nedim Doral, kongre başkanı Sayın Prof. Dr. Sinan Seber ve kongre genel sekreteri Sayın Prof. Dr. Hakan Ömeroğlu hocalarımızın desteği ve motivasyonu ile FORTE konulu oturum gerçekleşmiş ve FORTE'nin önceki başkanı Dr. Enis Güryel (UK) "FORTE Nedir? Amaçları Nelerdir?” başlıklı bir konuşma yapmış ve ülkemizin asistan eğitimindeki hassasiyeti bir kere daha gösterilmiştir.

Gerek sosyal gerekse bilimsel paylaşımın artmasını ve pekişmesini sağlayan bu organizasyon sonucunda ortopedi ve travmatoloji eğitiminde bizlere büyük katkısı ve desteği olabilecek projeler üretilmiştir. Üretilen bu projeler Ocak 2012'de Mersin'de düzenlenen Ortopedi ve Travmatoloji Temel Bilimler ve Araştırma Okulu sırasında TOTBID ve TOTEK yönetim kuruluna sunulmuş ve destek görmüştür. Hedeflenen projeler içerisinde; İsveç Karolinska Üniversitesi'nde devam etmekte olan Ortopedik Travma konulu "FORTE Fellowship" programı gibi programların birçok konuda ve tüm Avrupa genelinde yaygınlaştırılması, önemli yayıncı kuruluşlar ile yapılan asistan eğitiminde yardımcı kaynak olabilecek kitap serisi anlaşmasıyla -ülkemizin de misafir editörlüğünü yapacağı üç sayısının olduğu- 36 sayıdan oluşan kitap serisinin çıkartılması ve Avrupa genelinde sosyal paylaşımın arttırılması vurgulanmıştır.

Geçtiğimiz aylarda Londra'da düzenlenen EFORT 2014 toplantısında yapılan FORTE oturumunda, yeni yönetim kurulu seçimi gerçekleşmiş ve TOTBID/AGUH adına Dr. Gazi Huri bu genç ve dinamik ekibin başkanlığına seçilmiştir (Şekil 2).

Kurulduğu yıldan itibaren Türk milli ortopedi ve travmatoloji kongrelerinde oturum düzenleme şansı

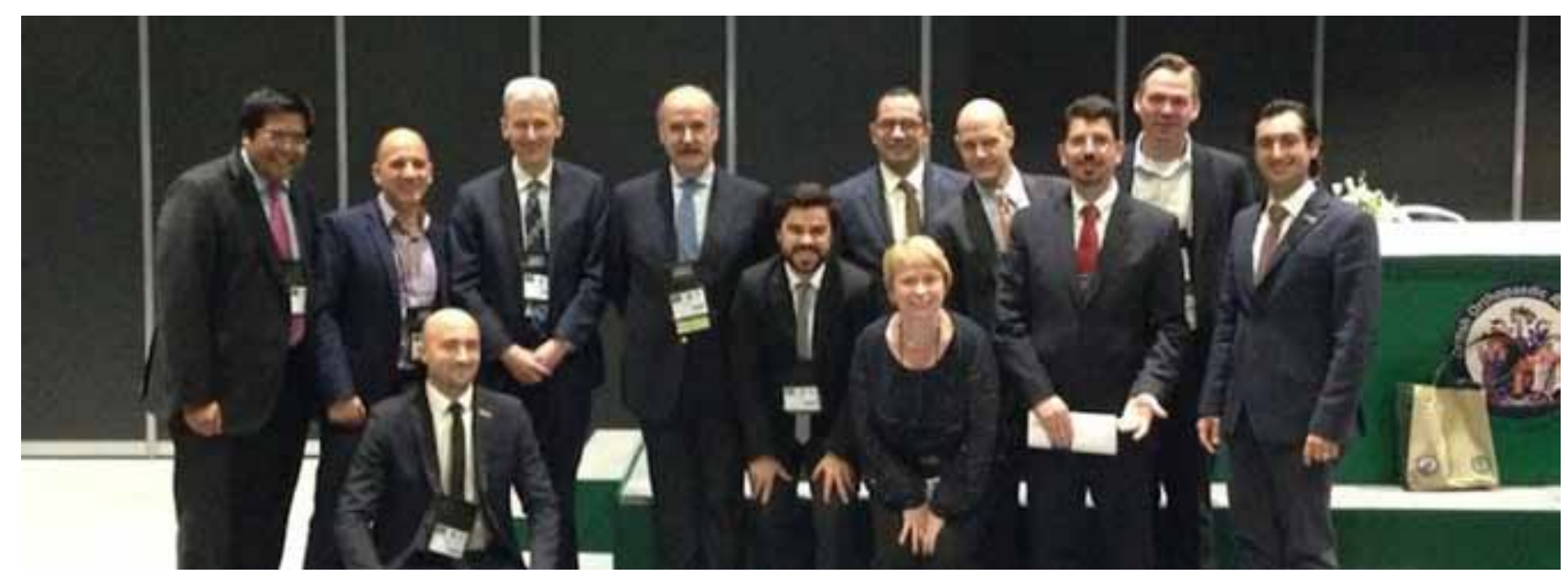

Şekil 2. EFORT-FORTE 2014 oturumunun ardından FORTE yönetim kurulu, EBOT başkanı Dr. Jorge Minerio ve Orthobullets kurucusu Dr. Derek Moore (Londra, İngiltere). 
yakalayan TOTBID/AGUH Konseyi, tanınan bu önemli olanağı en faydalı şekilde kullanmayı amaçlamaktadır. Bu olanağın, ortopedi ailesinin genç bireylerinin fikirlerini rahatlıkla paylaşabileceği bir ortam sağlamasının yanı sıra ülkemizdeki genç popülasyonun birbirini tanıması ve hekim-hekim ilişkilerinin geliştirilmesinde önemli yere sahip olduğu kanaatindeyiz. Yine aynı yıl İstanbul'da düzenlenen EFORT kongresinde FORTETOTBID/AGUH işbirliği ile organize edilen FORTE oturumunda, genç meslektaşlarımızın yoğun katılımı ile etkin bir tartışma ortamı sağlanmış ve toplantı büyük bir başarı ile sonuçlanmıştır.

Ayrıca, geçtiğimiz yıl TOTEK-TOTBID/AGUH işbirliği ile hazırlanan, Türkiye'deki asistanların neredeyse tümünün katılımının sağlandığı "Asistan Memnuniyet Anketi" ve bu yıl gerçekleştirilen "Hekime Şiddet Anketi" başarı ile tamamlanmıştır ve bilimsel yayın olarak yayımlanacaktır. Kısaca, bu anketlerden alınan sonuçlardan öne çıkan başlıklar arasında, asistanların araştırma yapmaya yeteri kadar zaman bulamıyor olması ile asistan bilgi ve seviye değerlendirme yöntemlerindeki eksiklikler başta gelmektedir. Bu eksikliklere benzer sorunlar, March ve arkadaşlarının 2014 yılındayaptıkları çalışmada da belirtilmiştir. ${ }^{[7]}$

\section{TOTBID-AGUH VE GELECEK}

'Gelecek gençliğin ellerinde şekillenecek.' söyleminden yola çıkılırsa, ortopedi ailesinin genç mensuplarına düşen rol yadsınamayacak kadar önemlidir ve çetindir. Geleceğimizi şekillendirirken amacımızın yalnızca mevcut pozisyonu korumak değil, aynı zamanda bilimimizi, camiamızı ve ülkemizi yükseltmek ve yüceltmek olması gerektiği aşikârdır. Bunun da ancak güzel ahlakı, milli ve manevi değerlerimize bağlı kalmayı, tarihimizle gurur duymayı, bununla birlikte yüzümüzü de sürekli geleceğe dönük tutmayı öngören ilkelerin ayakta tutulması ile sağlanacağına inanmaktayız.

Son olarak, asistanların ve genç uzmanların sorunlarını tartışabilecekleri ve çözüm önerilerini üretebilecekleri bir yapılanma olan, asistanlık döneminde yaşanan eğitim ve özlük hakkı problemleri ile uzmanlığın ilk yıllarındaki mecburi hizmet, istihdam ve akademik gelişim sorunlarını TOTBID ve TOTEK yönetim kurullarında doğrudan aktarabilecek bu dinamik grubun oluşmasında; TOTBID ve TOTEK Yönetim kurulu üyelerinin verdikleri destek, bilgi ve paylaştıkları tecrübeler ve ortopedi biliminin ülkemizde gelişmesine büyük emekleri geçmiş, önderlik yapmış, bizlerin rol modelleri olan tüm saygıdeğer hocalarımızın ilkeleri gösterge olmuştur.

Türk Ortopedi ve Travmatoloji ailesinin en genç grubunun çok uzun yıllar daha içindeki heyecanı, coşkuyu arttırarak çalışmalarına devam edeceğine ve bunun başta Sayın Onursal Başkanımız Prof. Dr. Rıdvan Ege ve Siz değerli hocalarımızın destekleri ve genç meslektaşlarımızın katılımı ile gerçekleşeceğine inancımız sonsuzdur.

\section{KAYNAKLAR}

1. Wolf BR, Britton CL. How orthopaedic residents perceive educational resources. lowa Orthop J 2013;33:185-90.

2. Royal College of Physicians and Surgeons of Canada. CanMEDS: better standards, better physicians, better care. Available from: http://www.royalcollege.ca/portal/page/ portal/rc/resources/aboutcanmeds

3. Egol KA, Dirschl DR, Levine WN, Zukerman JD. Orthopaedic residency education: a practical guide to selection, training, and education. Instr Course Lect 2013;62:553-64.

4. Marker DR, LaPorte DM, Seyler TM, Ulrich SD, McGrath MS, Frassica FJ, Mont MA. Orthopaedic journal publications and their role in the preparation for the orthopaedic in-training examination. J Bone Joint Surg Am 2009;91Suppl 6:59-66. CrossRef

5. Confederation of Postgraduate Medical Education Councils. Australian Curriculum Framework for Junior Doctors (ACF). Available from: http://www.cpmec.org.au/Page/australiancurriculum-framework-for-junior-doctors-acf-menu

6. Berkenbosch L, Schoenmaker SG, Ahern S, Søjnæs C, Snell L, Scherpbier AJ, Busari JO. Medical residents' perceptions of their competencies and training needs in health care management: an international comparison. BMC Med Educ 2013;13:25. CrossRef

7. Marsh JL, Potts JR 3rd, Levine WN. Challenges in resident education: is the Next Accreditation System (NAS) the answer?: AOA critical issues. J Bone Joint Surg Am 2014;96(9):e75. CrossRef

8. Huntington WP, Haines $\mathrm{N}$, Patt JC. What factors influence applicants' rankings of orthopaedic surgery residency programs in the National Resident Matching Program? Clin Orthop Relat Res 2014;472(9):2859-66. CrossRef 